Cuadernos de Trabajo Social

ISSN: 0214-0314

\title{
A vueltas y de vuelta a la miscelánea. Presentación del número
}

\section{[en] Going in rounds and back to the miscellany? Presentation of Numer}

El pretexto de esta presentación es doble: por un lado, hallar la coherencia en la diversidad de los artículos que integran esta miscelánea. Por otro lado, anunciar que Cuadernos de Trabajo Social interrumpe la sección monográfica, lo que no impide que se puedan publicar artículos sobre un tema concreto, y opta por la miscelánea, que tampoco es ninguna novedad, ya que siempre ha acompañando a aquella sección.

En esta miscelánea los artículos son variados: investigaciones y revisiones bibliográficas, que sistematizan resultados empíricos e informan de los avances y las tendencias de desarrollo disciplinar, y ensayos que plasman discusiones teóricas fundamentadas. El conocimiento que emana de todos los artículos, en especial de los de Trabajo Social y Servicios Sociales, fortalecerá, sin duda, su saber académico y profesional. En torno a ellos pivotan los conocimientos de otras materias que, en mayor o menor medida, contribuyen también a su consolidación científica. El contenido y la autoría - tres de los artículos se publican íntegros también en inglés- incrementarán la calidad y difusión del pensamiento y la práctica de Trabajo Social y Servicios Sociales en España y en América Latina y África.

En el primer bloque se aborda la construcción del conocimiento bajo una diversidad de perspectivas epistemológicas, algunas de las cuales cuestionan los fundamentos tradicionales del Trabajo Social en Europa y América Latina; y otras dan cuenta de la epistemología, hegemónica durante mucho tiempo, también en Trabajo Social, enfatizando los procesos de formación y disolución de ideas, valores y categorías, con esa particular mirada que suelen lanzar algunos académicos de las ciencias sociales. Los dos primeros artículos cuestionan la epistemología hegemónica positivista del
Trabajo Social; abren paso y escuchan otras voces que abogan por el protagonismo de los sujetos situados, aquellos que intervienen y con quienes intervienen la profesión y la disciplina de Trabajo Social. Van liberándose poco a poco, pero no sin dificultad, de la imposición de tener que adaptarse al método científico que, durante mucho tiempo, ha ceñido a las ciencias sociales como un corsé, con las varillas de la objetividad, naturalización y neutralidad, pero sobre todo con aquella que oprimía todavía más al Trabajo Social: la que dividía el trabajo científico entre quienes producen el conocimiento y quienes lo aplican.

Este análisis lo plasman Martínez y Agüero en La producción de conocimientos en Trabajo Social, cuando revisan aquellos autores de avanzada en clave decolonial en la construcción de conocimientos en Trabajo Social, cuestionan el eurocentrismo positivista excluyente, y refuerzan esta mirada con aportaciones procedentes de otras epistemologías, como: la feminista, la epistemología del Sur y la epistemología de frontera. La teoría feminista crítica persigue objetivos liberadores, deslegitima la opresión del pensamiento hegemónico de la modernidad por uniformador del conocimiento en el único -y excluyente- centro del saber occidental. La mirada meridional enriquece el conocimiento como acción, no como renuncia, y como crítica social emancipadora para la actuación política y la transformación social. En fin, con la epistemología de frontera, la gran autonomía intelectual se demuestra en buscar cómo erradicar el saber de las fronteras del sistema-mundo-moderno-colonial. Por su parte, los autores del artículo proponen un giro epistemológico que transforme el orden y la producción de conocimientos en Trabajo Social de la "rebeldía epistémica de la disciplina a la indisciplina", que permita reconstruir y 
consolidar una teoría social que desborde, exceda, traspase o atraviese las disciplinas. Una mirada interdisciplinar nueva, ni dicotómica ni fragmentaria, pero que tampoco abstraiga al sujeto del conocimiento y de la realidad histórica.

Un reflejo de esa línea crítica, más complementaria que antagónica, del conocimiento feminista lo expresa Martín Estalayo en El Orgullo en Trabajo Social. Su revisión histórica del saber epistemológico del Trabajo Social, es también una profundización en los viejos y nuevos retos que han afrontado y afrontan las profesionales y académicas en España, como sujetos históricos en pugna por conquistar nuevos espacios de poder; sobre toso el que ha enfrentado esta joven disciplina para generar un conocimiento emancipado. La calidad de este artículo está en la crítica al empirismo positivista y la apuesta por no entrar en el juego de competencias, que proponen otras ciencias sociales con una trayectoria más afirmada, sino más bien en buscar las interdependencias en un saber epistemológico complementario, que no considere el artesanal un saber "menor"; pero que tampoco desconfíe de una disciplina que ha sido construida, sobre todo, por unas mujeres conscientes de su poder, de su conocimiento y de su sensibilidad ante el sufrimiento social, que son quienes han cimentado la intervención profesional en la realidad de la desigualdad social, económica, política, jurídica, etc. Es por ello por lo que la dimensión de género es imprescindible para analizar relaciones de poder y de desigualdad como las indicadas anteriormente; como también lo son las aportaciones de las mujeres que han debatido acerca del objeto de la profesión, buscando sustanciar el campo de acción del Trabajo Social con métodos y técnicas propios. Con la mirada emancipadora de la acción social han ido "avanzando poco a poco con nuevos modos de saber que mejoraban notablemente su hacer"; han integrado teoría y práctica en un Trabajo Social que ha contribuido al cambio y a la mejora social, y ha fortalecido en este accionar el ensamblaje de la identidad profesional. Es en esta praxis donde la autora sitúa ese "orgullo de la trabajadora social" del primer cuarto del siglo XXI, en su impulso para "construir y reconocer una profesión y disciplina adulta, emancipada, independiente y capaz de contribuir a los nuevos retos de la sociedad", dice Martín Estalayo.
Una construcción del conocimiento institucional y con una perspectiva analítica más convencional, se puede leer en El Trabajo Social como forma de control de Morán Carrillo y Flores Sánchez. Este ensayo sociohistórico de los orígenes de la acción social, principios, organización y control de la pobreza y la desigualdad. Resaltan cómo se fueron generando las subjetividades y se transmitieron certidumbres, a través del ejercicio del poder de la Iglesia católica y el Estado. Estudian la función de control -y de mediación- del Trabajo Social entre estas instituciones -no menos controladoras - de poder y de magistratura frente al creciente pauperismo urbano y rural. Organizaciones en constante pugna por ampliar sus espacios de poder, en cualquiera de sus líneas de acción: por un lado, el interés del Estado en racionalizar, reordenar y centralizar la toma de decisiones mediante unas políticas reformistas, en mayor o menor grado; y por el otro, la agitación social e ideológica del asociacionismo socialista de entonces que le apremiaba a buscar la mediación de los trabajadores sociales para frenar - dicen los autores- la fuerza del sindicalismo obrero progresista entre las masas trabajadoras. Por su parte, la Iglesia como institución "acostumbrada a ejercer el monopolio benéfico como algo propio", tampoco estaba dispuesta a perder ningún espacio de poder y los espacios sociabilidad analizados - las asociaciones confesionales, los congresos y las escuelas de Trabajo Social - eran resquicios que había que ocupar, no tanto por cuestiones morales sino para disponer de estos espacios de poder bajo su hegemonía. Los espacios de sociabilidad y de formación del Trabajo Social que se reseñan en el artículo contribuyeron, por lo tanto, al proceso de toma de conciencia de la necesidad de incorporar mejoras técnicas para profesionalizar las prácticas de la asistencia social. Las fuerzas que empujaron hacia la profesionalización de la intervención social y su identidad corporativa, según estos autores, fueron en gran medida de naturaleza exógenas al Trabajo Social.

Los artículos siguientes ahondan en la necesidad de reformar el Sistema de Servicios Sociales en su doble nivel - atención primaria y atención especializada- treinta años después de su implantación; así como. Buscan, además, redefinir el objeto y la práctica, la gestión y financiación del sistema; y para ello, aportan marcos teóricos, enfoques y métodos diversos, que les llevan a conclusiones de gran interés 
para los lectores. Analizan las funciones de los profesionales de la intervención social en diferentes campos -sociosanitario, socioterapéutico, socioeducativo, medioambiental - y las competencias que les atribuyen normas, programas o protocolos. Se plantea desde hace años la exigencia de unas reformas que se han ido aplazando, y al final, en su lugar se hayan impuesto aquellas de los gobiernos que recortan los gastos sociales, que a los servicios sociales han afectado de forma particular. Los dos primeros artículos son regionales y sus alcances tienen dimensiones diferentes: uno, detalla los términos en que se está llevado a cabo el debate en la Comunidad Autónoma de Navarra y, entre sus objetivos está extenderlo a todo el país, y más allá si fuera posible, a través de la comunidad de lectores de Cuadernos de Trabajo Social; el alcance del otro artículo, es más limitado, la función de los profesionales socio-sanitario en un dispositivo de la Comunidad Autónoma de Canarias. Sin embargo, por tratarse de un tema inexplorado, es de interés para una investigación comparada en un futuro. Difieren no solo en el objeto, sino en la metodología de análisis y, como consecuencia, también en los resultados. Sin embargo, ambos transmiten las inquietudes sobre la modificación de los roles de los profesionales de la intervención social: roles asignados, roles asumidos y roles cuestionados en la mayoría de los casos.

Así en El modelo de Atención primaria de Servicios Sociales a debate, Martínez Virto y Pérez Eransus aportan los primeros resultados de una investigación-acción-reflexión realizada en Navarra, para que profesionales y académicos conozcan los términos del debate sobre la reforma del sistema de Atención primaria de Servicios Sociales en el contexto de la nueva cuestión social, así como el cuestionamiento de la universalidad de los derechos conquistados. Algunos elementos clave del debate son: la acentuación de dilemas sobre el objeto y los sujetos potenciales de los servicios sociales; la necesidad de desarrollar nuevas estrategias de acción para impulsar el Trabajo Social comunitario, así como otras numerosas aportaciones del artículo, señalan que hay que recuperar la "cultura de servicio", que es la lógica de la solidaridad indirecta de unos servicios sociales públicos. Explican que la falta de recursos y el incremento de demandas, que no se pueden atender, están obligando a replantearlos, y ponen también en duda la consolidación de los derechos universales adquiridos. Todo ello está contribuyendo a desdibujar también la figura del trabajador social de referencia y diluir la intervención social con individuos y con grupos, lo que convierte al profesional de trabajo social en un gestor de casos, de conflictos o de recursos, desfigurando también su identidad. Las autoras anotan que rediseñar la compatibilidad de la atención primaria en un contexto de demanda elevada como el presente, obliga a establecer prioridades -los resultados de la investigación así parecen indicarlo- para asignar recursos. Ello significa cuestionar la universalidad de los derechos sociales -aunque las autoras no lo plantean en clave dicotómica- o, por lo menos, una cierta renuncia o una condicionalidad de acceso, al establecimiento de categorías de necesidad detectadas en el usuario demandante. Ello llevará a otra parcelación y una debilitación más del sistema de atención primaria, pero esta vez, en aras de esas "prioridades" decididas según la gravedad de las necesidades, expuestas ahora con criterios de adaptación a la realidad: la de escasez de recursos públicos para ofrecer a los usuarios.

También Abreu Velázquez y Mahtani Chugani, en Las funciones de los trabajadores sociales sanitarios en Atención primaria de salud, abordan la atención primaria, aunque esta vez desde la perspectiva del trabajo social sanitario: su evolución, redefinición y los desafíos del rol profesional del trabajador social. Se trata de una revisión documental de una década (1988 a 2008) de programas, protocolos y otros documentos del Servicio Canario de Salud, con objeto de comprobar el grado de adecuación a las necesidades actuales de la institución y a las nuevas demandas de la población. Las autoras señalan la naturaleza exploratoria y limitada de su estudio, que no está reñida con el interés, al no existir estudios similares al suyo en España. Entre los resultados más relevantes señalan: el carácter polivalente del trabajo social sanitario; la prevalencia de intervenciones en atención directa y orientación al trabajo con individuos, cuando abordan los problemas sociales; y se les reconoce sobre todo como gestores de casos, de aquellos que encierran una problemática social, cuando intervienen con grupos concretos (menores, con discapacidad y personas mayores). Las autoras señalan la modificación del criterio que, anteriormente, tenían los profesionales acerca de las familias: se ha pasado de considerar- 
las uno de los sistemas de interacción social a considerarlas un elemento instrumental para proporcionar cuidados. La adaptación realista en este caso cobrea otro cariz respecto al artículo anterior: se trata de acomodarse más a las exigencias actuales del sistema sanitario que a las de la intervención del Trabajo Social. No es de extrañar la vuelta -nunca se abandonóal modelo mediterráneo del cuidado familiar, caracterizado por un nivel alto de cuidado informal y un escaso desarrollo de los servicios de atención residencial públicos. Sin embargo hay una cuestión que llama poderosamente la atención: "la escasa relevancia del diagnóstico social en el rol normativo", siendo como es competencia específica del profesional de la intervención social, lo que puede estar avisando de un intento soterrado de desregulación profesional de los trabajadores sociales en el ámbito sanitario.

El siguiente bloque de cuatro artículos se refiere al Trabajo social en el ámbito educativo; los primeros hacen referencia a la función de los profesionales en las instituciones de educación obligatoria en España; y los dos siguientes son reflexiones sobre las representaciones de los estudiantes universitarios de Trabajo Social en el espacio educativo superior latinoamericano. Es un lugar común para la intervención social considerar la escuela obligatoria, el terreno más apropiado para detectar las primeras situaciones problemáticas familiares y sociales; aquel en que los profesionales del Trabajo Social asumen roles diversos y determinadas funciones tanto en la gestión de situaciones de conflicto como en el acompañamiento hacia la emancipación de los grupos e de los individuos que los sufren.

De este modo, el ensayo de Martínez González, Repensar la intervención social con grupos, es una reflexión de carácter teórico, basado en la práctica profesional del autor en intervención social con grupos y supervisión de equipos. Con un enfoque interdisciplinar -educativo, social y psicoterapéutico- aborda la intervención social con grupos para contribuir a mejorar la práctica profesional. Realiza una cuidadosa revisión teórica de aquellos autores cuya contribución al conocimiento del Trabajo Social con grupos está afirmada, y de otros cuyas teorías "frecuentemente desconocidas por los profesionales de la intervención social". Establece algunas diferencias conceptuales e invita a detenerse para reflexionar acerca de la complejidad de las interrelaciones que mueven los grupos socioeducativos - "los que se congregan en torno al abordaje de una necesidad formativa"- así como los socioterapéuticos -"los convocados para compartir y abordar un padecimiento o una herida singular, pero con rasgos comunes". Resalta algunas diferencias conceptuales -grupo y agrupamiento- con objeto de que, en el ejercicio de su actividad, sea el grupo quien consiga quien tome la iniciativa y haga alorar la pluralidad de los sujetos, activos y complementarios, que lo componen. No elude la posibilidad de un disenso que suele surgir en toda pluralidad humana, sino que, al contrario, hay que tratar de afrontarlo y de mantener la tensión. El autor entiende el grupo como un lugar seguro, en el que cada integrante se compromete a realizar - $\mathrm{o}$ a cuestionar- las tareas asignadas y aceptadas; incluye a los profesionales en los grupos y las tareas correspondientes, como miembros del mismo, les llevan a comprometerse con todas y cada una de las personas que lo integran, ayudando a construir el grupo, a abordar las dificultades y a que lo hagan sus integrantes. El grupo es un espacio de reflexión conjunta y por separado, y de un debate que se configura como un objetivo emancipador. Por lo tanto, se convierte en un espacio de poder compartido en el que la intervención grupal genera un sentido de pertenencia inicial, en un poder que luego se transforma en autonomía.

El conflicto en el espacio educativo es también el objeto del artículo, Trabajo Social y mediación, de Iglesias Ortuño y Ortuño Muñoz. Las autoras abordan la función de mediación del Trabajo social con una perspectiva sistémica. Estudiar el estado de la cuestión de la mediación escolar en España e indagar en la oportunidad social que brinda la cultura de la mediación en las escuelas y las aportaciones de la intervención del Trabajo Social en su impacto social son los objetivos de este artículo. Se ha realizado un análisis bibliográfico de referencia en mediación social, como instrumento cualitativo. El objetivo de la práctica profesional en las instituciones educativas, según las autoras, es promover estrategias de intervención y unas estructuras organizativas que faciliten la convivencia en la comunidad educativa en su conjunto. Distinguen un doble significado en todo conflicto: el de oportunidad para el crecimiento personal $\mathrm{y}$, por lo tanto, con una función regeneradora; y el de disrupción, que provoca una situación de sufrimiento y destrucción y victimiza al sujeto. Completan 
los conceptos con el doble posicionamiento del sujeto - activo o pasivo- ante el conflicto, sobre tos en relación al que se concibe como regenerador. Las autoras inciden en el significado más armonioso del conflicto, como oportunidad de implicación activa en la superación. Al considerar que los trabajadores sociales tienen que desempeñar la función de agentes activos en los centros educativos, no solo por la formación recibida, que les hace habilidosos en técnicas, estrategias y procedimientos eficaces, sino porque ellas les capacitan para descubrir las causas profundas de los conflictos que afloran en el espacio escolar, y, por lo tanto, para mediar en su solución de forma pacífica y profesional, sin perder de vista la oportunidad de mejora que brindan los conflictos.

La investigación de Pérez Álvarez, Figuras para resignificar la práctica profesional de Trabajo Social, aborda la complementariedad de la teoría con la práctica, a partir de las aportaciones del interaccionismo simbólico. Entiende la práctica como acción con sentido: como campo que construye conocimiento y soporte para la resignificación de la intervención social; y no tanto como un espacio para su verificación sino para cuestionar, incluso, los sistemas de dominación sobre los que se ha erigido el Trabajo Social. Las categorías que se abordaron en los grupos de discusión y reflexión, con los estudiantes colombianos de Grado en Trabajo Social, fueron los procesos de intervención y la construcción teórica y metodológica de la intervención en Trabajo Social. En el artículo se presentan los resultados de una investigación sobre las representaciones que se han ido formando durante la carrera, y cómo las han plasmado en las prácticas curriculares, previas a su graduación universitaria. Se amplía la investigación al compromiso institucional -denominado "extensión universitaria- dedicado a la gestión y al desarrollo de las interdependencias entre las funciones básicas de las universidades -la docencia y la investigación- y la lógica de servicio público que, como la universidad debe rendir a la sociedad por lo que esta ha aportado como inversión social en la formación de los futuros profesionales: como una "apuesta de proyección social e incidencia en la transformación de condiciones de vida". En los grupos de discusión con estudiantes han surgido cuestiones conceptuales y vivenciales que invitan a recapacitar en las relaciones entre disciplina y profesión, teoría y práctica, y en la implicación de estos sujetos situados, en el proceso de reflexión-acción-transformación..La importancia del análisis de contexto, como componente clave de la intervención profesional, cierra el círculo de la fundamentación teórica; la sistematización de la experiencia; la participación de los sujetos y la definición de la metodología.

En un contexto de educación superior se analizan los estudios de posgrado como espacios que favorecen darse el "lujo de pensar". En La generación de conocimiento en Trabajo Social, Figueroa Reyes aborda la iniciación en la práctica investigadora de los estudiantes que confluye en los trabajos de fin de Máster. Compara dos programas de postgrado chilenos, con la finalidad de conocer el impacto de las competencias adquiridas, en el desarrollo profesional y en la difusión posterior de conocimientos de mayor calado. Como el eje fundamental con el que desentrañar nuevos métodos que permitan conocer mejor la realidad, es el investigador (sujeto y objeto de observación) un elemento central para quien estudia Trabajo Social. La mirada de las estudiantes encuestadas -mujeres su mayoría- acerca de las aportaciones de esta práctica investigadora y el tipo de pensamiento que deriva de los trabajos de graduación han de conseguir producir, promover y divulgar un conocimiento más sistematizado de la intervención social. Que los trabajos de fin de Máster de los dos perfiles comparados - la disciplina de Trabajo Social y las políticas sociales - tengan carácter promocional no se niega. No obstante los resultados arrojan datos más positivos en lo académico que en la posible incidencia en las políticas sociales. Con estas investigaciones se adquieren herramientas - dice la autora- que facilitan el acceso a la docencia y la investigación, y también aquellos conocimientos y destrezas que sirven a las políticas sociales, en alguna de las fases. En relación al carácter innovador de estos trabajos - diseño, ejecución o análisis de resultados - las graduadas son poco autocríticas. Quizá esto sea el motivo por el que solo algunas estudiantes llegan a publicar los resultados de su investigación en revistas científicas. De ahí que la contribución de estas prácticas investigadoras iniciáticas a la generación de conocimiento sea reducida.

En Asignación de servicios sociales a personas mayores, Iglesias Souto, Real Deus, Dosil Maceira, Mayo País y Taboada Ares, (presentado también en inglés), constituye una revisión bibliográfica de repositorios y datos 
que sistematizan resultados e informan de las tendencias de interés para la disciplina; además, indagan acerca de los sistemas que asignan recursos de acuerdo con perfiles y necesidades de las personas mayores en situación de dependencia. En España, en los últimos años, aunque se ha producido un aumento significativo de recursos de servicios sociales, sobre todo residenciales -dicen los autores- no están sincronizados con las demandas ciudadanas, y por ello la oferta sigue siendo insuficiente para cubrir las necesidades actuales. La mayor parte de los artículos reseñados se refiere al perfil o a los factores que prevén el uso de los distintos servicios sociales por este colectivo de personas mayores, pero ninguno se trata de los modelos que ayuden a los profesionales a tomar decisiones de cómo asignarlos. En relación al primer caso, las variables de uso de los servicios sociales analizadas son los dispositivos - centros de día, residencia, apartamentos tutelados, ayuda a domicilio, etc.- y sus categorías -sociodemográficos, de salud y bienestar físico y cognitivo y de apoyo social-así como los modelos y sistemas de asignación, según el perfil de las personas mayores demandantes. La asignación por similitud de perfiles Fundación SAR y Balance of Care- se concibe como una estrategia de planificación de la asistencia sociosanitaria, prevalece la atención de comunitaria sobre la residencial. Sin embargo, los autores proponen, para el segundo caso, un modelo de toma de decisiones diferente, basado en otras variables de pronóstico (externas e internas) con que identificar tanto los perfiles de los usuarios como los apoyos pertinentes; modelo que contribuye a facilitar la labor profesional de toma de decisiones de carácter social y gerontológico, y a la gestión de las políticas sociales para este colectivo, dicen las autoras.

Otra temática abordada en la miscelánea, que cobra cada vez mayor relieve, es el endeudamiento por una variedad de opciones de gobierno $^{1}$. Profundizan en la conversión de los usuarios de los prestamos en clientes financieros, para mantenerse vivos o para estudiar en deudores, por haberlos solicitado (y tener que reembolsarlos) para afrontar las necesidades y en deudores in natura por tener que capitalizar sus conductas, actitudes, proyectos en invertir sus tiempos en actividades que le permitas saldarlas, como buscar empleo y resignarse a aceptar lo que se le ofrezca, o en una formación continua para no estar sin hacer nada. Las políticas financieras neoliberales plantean la carencia de recursos como un riesgo individual, más bien como una oportunidad de superación individual para salir de la trampa de la pobreza. En los siguientes artículos se analizan las repercusiones del endeudamiento en América Latina, de esta lógica del capitalismo financiero y de cómo se explota a los consumidores individuales con el endeudamiento. El primer artículo se ubica en Argentina y el segundo en Chile.

Frente a la mirada del riesgo como oportunidad de algunos académicos y profesionales, en el ensayo Pagar la deuda social, Campana Alabarce critica las propuestas financieras de la reforma política, laboral y de previsión social que -como el nombre de "Cambiemos"está imponiendo la alianza de partidos que integran el gobierno argentino de Mauricio Macri. Exigen del Estado que active unas medidas para reformar el mercado laboral y la previsión pública nacional radicalmente. Para ello establecen algunas medidas desreguladoras de lo público, como son: nuevos marcos reguladores a favor de los mercados, de los fondos de capitalización privada, de la negociación salarial por la empresa y del seguro privado, ante los posibles despidos que se prevén. Se podría hablar de una "reconceptualización" desreguladora de la política social neoliberal argentina. La autora plantea el giro de aquel sistema público estatal precedente, más o menos garantista en protecciones sociales, a otro protagonizado por los recortes de derechos en protección social. El nuevo modelo sitúa a los ciudadanos precarizados en una posición crítica: la de deudores; o como consumidores de unos créditos que tuvieron que contraer para afrontar las situaciones de desprotección social sobrevenidas. Esta degradación estructural, como efecto de los recortes activados por estas políticas, se encubre como la oportunidad que le brinda al deudor este riesgo individual, cuando en realidad lo que enmascara es un riesgo de naturaleza colectiva, como lo había

Pozzi, Sandro (2017). El impago de la deuda estudiantil se dispara en Estados Unidos. El País, 21 de mayo. De Barrón, Íñigo (2018). Primer embargo judicial por no devolver un prestamo universitario del ICO. El País, 14 de mayo. Se denomina "Prestamo Renta Universidad", una línea de crédito del Instituto de Crédito Oficial para estudios universitarios de posgrado que se concedió entre 2007 y 2011. La línea tuvo cerca de 12.000 beneficiarios y lo creó el Gobierno de José Luis Rodríguez Zapatero, a través del Ministerio de Educación. 
sancionado el sistema de protecciones públicas precedente. La autora profundiza en la franja de la desigualdad que genera endeudamiento, a todos los niveles y en todos los aspectos de la vida, hasta convertirse en una forma intensificada de explotación, que se conoce como "servidumbre por deuda". Las reformas de "Cambiemos", al armonizar el riesgo y considerarlo una oportunidad individual, camuflan la igualdad en el acceso a los bienes sociales con el criterio de equidad; y el de ciudadanía con el de mérito. Se alejan así del carácter universal con que se establecieron las protecciones sociales para aquellos ciudadanos, que por los motivos que fueran - en su mayoría a causa de las políticas de reajuste económico y financieras- estaban sumidos en una precariedad grave. Los usuarios se convierten ahora en clientes-deudores, mientras no devuelven los créditos; en consumidores de un recurso que les exige dedicar su tiempo, en cuerpo y alma, a buscar trabajo o estar de formación continua para mejorar la cualificación en un mercado de empleos precarios, pero que le permita salir de la servidumbre de ese prestamo bancario. Las políticas de "Cambiemos", pretenden convencer de que la pobreza y la precariedad se pueden convertir en el capital del deudor-consumidor de créditos y, a la vez, en ese espacio económico en que asume y afronta sus riesgos solo, donde se transformado en un empresario autónomo de su precariedad, y donde esta situación le brinda además la oportunidad de autorrealización moral, ya que activa y administra su tempo en saldar la deuda.

Las expectativas que se ponen en la educación superior como un trampolín para alcanzar un futuro mejor suelen ser las mismas para los estudiantes con recursos que para quienes por no tenerlos, han de recurrir a prestamos para realizar esos proyectos. También en Gobernados por las deudas, Lorena Andrea Pérez investiga la servidumbre de la deuda individual - esta vez la del sistema Corfo (1997-2011)que sujeta a aquellos estudiantes universitarios chilenos que no pueden realizar de otro modo sus estudios universitarios. El ensayo se encuadra en los estudios de "gubernamentalidad", analiza la penetración de las estrategias y prácticas financieras y su influencia en la acción del Estado y sus modos de gobernanza, transformando a los usuarios en clientes eficientes y capaces de tomar "sus decisiones individuales responsables e informadas en tanto consumidores de servicios y otros bienes".
Así es como -según la autora- se venden los prestamos Corfo chilenos. En este sistema crediticio de encierra en el círculo de sujetos financieros a estudiantes y a sus avalistas solidarios, y se transforman en deudores y codeudores solidarios respectivamente, tanto durante el periodo de estudio como al inicio de su ejercicio profesional. Se les introduce en el engranaje bancario - como sujetos subalternos y disciplinados - y se condiciona su conducta al pago de unas obligaciones crediticias. La autora analiza el proceso de transformación de "sujetos pobres" en "sujetos financieros", y su extensión con la exigencia de un aval periódico, para protegerse de los riesgos, pero que comporta un elevado coste económico y personal para los estudiantes deudores el tener que cumplir mensualmente antes del vencimiento de los plazos. Este artículo abre una ventana para que entren aires críticos con construcciones analíticas que abandonan las nociones binarias y moralizantes de la responsabilidad del deudor, de las que está atravesado el Trabajo Social, y plantean la necesidad en pensar en nuevas formas de solidaridad y colaboración que comprendan el endeudamiento como un problema social, cuyas respuestas dependen del conjunto de la sociedad, como apunta la autora.

El repliegue de las políticas en vivienda social urbana para la población de bajos ingresos le condena a idear otro tipo de alojamiento - infraviviendas y agrupamientos precarios- al no poder acceder a otros por carecer de recursos o por ser insuficientes. Desde la perspectiva del Trabajo Social, se refuerzan bases teóricas, de la relación entre "la persona y su entorno" y las interacciones socioambientales de las comunidades vulnerables en estos asentamientos precarios. También se proponen políticas sociales de vivienda para mejorar las situaciones de las personas sin hogar de larga duración, y para evitar que las personas que recientemente han sido expulsadas del sistema de protección pasen inicien una situación que puede convertirse en definitiva. Se abordan estos temas tratando de potenciar la participación de las personas en situación de exclusión de vivienda ya sea desde al sector público, como del sector privado no lucrativo, es decir, de las entidades involucradas en la intervención con personas sin hogar.

El Trabajo Social relacional de Amorocho Pérez y Palacio Tamayo presenta la perspectiva de las interacciones socioambientales de 
las poblaciones desplazadas forzosamente en Colombia. Con el marco teórico de la relación entre "la persona y su entorno" de las pioneras de Trabajo Social, articulan la perspectiva relacional, dialógica y situada, delas redes socioambientales del lugar, y lo realizan con una mirada interdisciplinaria que comprende varios enfoques: la gestión participativa de las áreas protegidas; la construcción social del riesgo; y la gobernanza de los ecosistemas estratégicos. Con ello analizan y comprenden la estructuración de los vínculos que trenzan el riesgo social, tanto durante el proceso de construcción de los asentamientos precarios y sus relaciones, como con el territorio y su precariedad estructural; y también otros vínculos, no menos precarios, que establecen con las instituciones y los intereses políticos. Este ensayo muestra que los desastres que provocan las inundaciones de los asentamientos precarios son el resultado de varios factores: por un lado, la configuración socioambiental del riesgo que articula la migración de personas -con lazos de parentesco o amistad - con un territorio que ofrece elementos ecológicos para la autoconstrucción de viviendas; y por el otro, también las desarticula de la percepción de riesgo del entorno ecológico en el que asientan su precariedad. Las redes no solo se conforman como espacios de reflexión acerca de las formas de pensar y de actuar, sino que también informan del modo como se van estableciendo relaciones dialógicas entre los actores implicados, y se sancionan acuerdos colectivos que permitan construir espacios más seguros y sostenibles. Tanto a quienes reconocen la acción de los trabajadores sociales en entornos de desastre, y su colaboración con diversos actores; como a quienes critican muchas de las intervenciones porque pueden contribuir a mantener relaciones de poder de dominación-dominado, las autoras proponen que se descolonice la práctica del Trabajo Social en casos de desastre, ya que la información acerca de los procesos de estructuración de estos asentamientos son una fuente de información importante para construir procesos de diálogo y participación para los procesos de planificación y ordenamiento territorial de estos lugares y con estas interacciones.

Con una mirado socio-histórica centrada en las políticas sociales en España, Rubio-Martín, en De aquellos barros, estos lodos, analiza el Sistema público de servicios sociales en relación con las personas sin hogar, durante el periodo democrático que llega hasta la actualidad. Señala que le han quedado algunas "asignaturas pendientes" como son: no haber logrado erigirse como cuarto poder de protección social - por su desconexión con los otros tres poderes del bienestar social- y por no haber sabido vincular mejor la atención social a las prestaciones y los servicios con las personas en situación de pobreza extrema. A pesar de estos fallos en el sistema -numerosas dificultades y la pobre red de centros y servicios públicos para las personas sin hogar- se ha avanzado al modificar la visión de este colectivo, pasándolo al ámbito de lo social de la consideración precedente como un problema de orden y seguridad públicos. Ello ha comportado un cambio tan profundo como el del reconocimiento de las personas sin hogar como ciudadanas de pleno derecho. Eso sí, con ciertas peculiaridades psicosociales, que la atención social pública ha afrontado focalizándola más hacia la reconstrucción de los déficits personales y las habilidades psicosociales que a las políticas de prevención y atención a sus demandas. Quizá en su debilitamiento cuente también la poca afección de las personas sin hogar por los servicios sociales; máxime cuando son demandas que, aún proponiéndose atender la Administración local, han chocado con algunas resistencias de otros ciudadanos, en muchos casos perceptores también de ayudas públicas, pero en situaciones de pobreza menos aguda. No obstante existen programas, como los de rentas mínimas, para paliar algunos efectos del sinhogarismo, y en unas regiones la atención sea mejor que en otras, pero son insuficientes y muy rígidos, y por lo tanto de escasa eficiencia con este colectivo. Si a ello se añade que, tras la crisis se ha paralizado cualquier intento de mejora, y que incluso en los nuevos planes estratégicos de inclusión social, que son pertinentes para este colectivo, no se reportan otras actividades ni mejoras en la coordinación interadministrativa y con el tercer sector, que las que estaban ya diseñadas en los viejos planes, con dificultad se puede potenciar a las personas sin hogar como un sujeto social, sin que se le encapsule en su pobreza extrema. Hay que ofrecerle, en cambio, otras medidas y actividades que atiendan, además de sus problemas personales, las demandas de inserción social que favorecerán el acercamiento a una pobreza más integrada, y les faciliten espacios de participación donde se puedan expresar para defender y reclamar sus derechos. 
La intención de dotar de voz activa y reivindicativa a las personas sin hogar se refleja en la investigación de Jordi Sánchez. En Potencialidades y límites de la participación de las personas sin hogar, parte del análisis estructural y organizativo de Trabajo Social asociado a redes de poder, y de los dilemas éticos de aquellos técnicos que no osan formular críticas a la obsolescencia de los modelos de intervención profesional, aplicados en el momento presente, y que están contribuyendo a reforzar la función que se les asignaba convencionalmente a los trabajadores: la de ser agentes de control y de orden. Es una exigencia, en los últimos años, analizar la dimensión estructural del sistema, y la diversificación creciente respecto a hace unos años, en perfiles y en números, de este colectivo de personas, muchas de las cuales pertenecen a una clase media empobrecida por motivos, de naturaleza económica sobre todo, como son: desempleo, endeudamiento; también mujeres, jóvenes y extranjeros. Su objetivo es estudiar otras alternativas posibles de prevención y detección en el ámbito del sinhogarismo, que cuenten con la participación de las personas interesadas en este ámbito de la intervención social. Persigue con ello alterar y redefinir la composición de fuerzas en juego y los fundamentos técnicos, organizativos y políticos, para dotarles de mayor transparencia y apertura social. Entiende la participación como la restitución de una libertad negada a quien se estigmatiza y desposee de legitimación social; como devolución de su libertad para actuar en los procesos de intervención que les afectan.

Los últimos artículos abordan diversas temáticas, sujetos y contextos, bajo forma de son investigaciones y ensayos que interesan al Trabajo Social, tanto desde la perspectiva de la violencia de género, como de las posibilidades de mejorar las relaciones en contexto migratorios, entre personas con opciones sexual afines que utilizan como vínculo las redes de comunicación tecnológicas. Son artículos con perspectiva internacional, ya sea por el contexto en el que se desarrolla la investigación y por los autores que escriben los artículos.

El conocimiento de la diversidad de sujetos situados, y el análisis multifactorial de las diferentes opresiones de estas menores de edad -clase, raza, género- genera la diversificación y gravedad de la violencia de género en sus múltiples manifestaciones. En el contexto africano, Explotación sexual de niños, niñas y adolescentes de Bautista Cosa propone una mirada globalizadora del fenómeno de la violación de los derechos de la infancia en contextos de precariedad socioeconómica, donde la industria del sexo cosifica el cuerpo de las mujeres para consumo, y diversifica el "producto" en todo un mercado al detail: trata, prostitución, violación, pedofilia, pornografía, etc. En Madagascar, como en otras partes del mundo, donde la lógica de poder y de dominación patriarcal y patrimonial cae sobre las mujeres y los hijos, en los datos sobre la explotación sexual se refleja también la precariedad de las mujeres pobres, su limitado acceso al sistema de salud en general y la escasa información en salud sexual y reproductiva, en concreto. Además refuerzan este fenómeno unas mentalidades que otorgan una "legitimidad", real y simbólica, a la violencia de género en el ámbito familiar. Con diferentes marcos de conocimiento y de prácticas profesionales que, en un proceso de adaptación creativa, contribuyen a transformar esas realidades y a mejorar las condiciones de las niñas y niños malgaches, la autora aborda esta investigación, limitada a una asociación no lucrativa que estructura la protección y defensa de derechos de los menores en situación de explotación sexual, en ese país desde hace más de 10 años. Con una perspectiva feminista emancipadora y una postura híbrida respecto a la prostitución concede un papel importante a la intervención participada de las mujeres y jóvenes, involucradas en esta violencia, como acción basada en la evidencia y liderada por ellas. En el marco de análisis de los problemas de las menores -factores personales y familiares- detecta una limitación en los programas con los que se interviene, ya que no les implican ni a ellas ni a la comunidad, y mucho menos cuestionan la función de la clientela que las consume. De ahí que señale la importancia de modificar esta mirada hacia la participación, en aras de una mayor eficacia de las acciones que se emprenden y de las que se pueden activar en un futuro, para que respondan a las necesidades y los deseos de las jóvenes. Además, la autora señala la necesidad de una formación en violencia de género con menores de los equipos profesionales autóctonos, para que abandonen ciertos mitos y estereotipos que se centran exclusivamente en la conducta individual de la menor (inerte, pasiva ante su situación), y no ven ni dejan que se vean otros factores más profundos y macroestructurales, que son los responsables de que se solidifique esta violencia. Las recomendaciones de mejo- 
ra de las prácticas propuestas por la autora son realistas y de gran interés.

Con una perspectiva de mediación integradora de la diversidad sexual, La utilización de las TIC en la consolidación de las trayectorias afectivo-sexuales de Restrepo Pineda trata de la "tecnosociabilidad"; o lo que es lo mismo, la función mediadora de las tecnologías de la información y la comunicación en la integración de jóvenes colombianos homosexuales y bisexuales en la sociedad de destino. Estas personas utilizan a menudo las referencias a nuevos espacios de sociabilidad, en este caso España por varios motivos: por un lado, el reconocimiento legal de la pluralidad de opciones sexuales; y por el otro, el potencial de estos medios para desarrollar programas de promoción y prevención de salud sexual y reproductiva de los jóvenes. Ambos motivos, favorecen no solo el encuentro con nuevos contextos sociales, culturales y sexuales, sino la comunicación de trayectorias sexuales de origen con nuevas formas de relación y establecimiento de otro tipo diferente de vínculos afectivos. Entre los medios analizados, hay unas aplicaciones más ágiles y eficaces que otras para poner en contacto a varones y para construir otro tipo de relaciones íntimas. Lo analiza como un proceso cultural dinámico en el que se modifican los significados sobre la sexualidad en dos contextos diferentes. Sin embargo -dice el autor- el peso de las experiencias de los varones homosexuales y bisexuales colombianos determina la forma de integrarse y participar en España, y no solo con relación a las trayectorias sexuales, sino también a las nuevas formas de relacionarse y establecer vínculos afectivo-sexuales diferentes. Por otra parte, como las TIC tienen ya tanta importancia en promocionar y prevenir la salud sexual y reproductiva, es necesario que la información disponible en estos medios sea clara, precisa y confiable, recomienda el autor.

Con una mirada positivista, más biologicista e higienista que de intervención social, la investigación de Blanco Prieto, González Solares y Menéndez Patterson, La valoración del estado nutricional de usuarios de ayuda alimentaria, analiza en términos de seguridad alimentaria, la mejora nutricional de los grupos que reciben ayuda alimentaria, a la luz de la experiencia de una entidad privada implicada en esta acción. En esta investigación cuantitativa se comparan modelos de alimentación para determinarla existencia o no de diferencias en los modelos de consumo según la clase social : hogares de bajos ingresos o de clase media- para ver cuál es el menos saludable. Su objetivo es poder diseñar proyectos de ayuda alimentaria con la lógica de impacto social. Esta lógica tiene un triple objetivo: comprender "los retos y las necesidades del público objetivo... definir objetivos de impacto evaluables... y los pasos necesarios para gestionar un proyecto que logre cambios en la actuación del público objetivo, en su vida cotidiana y, en último lugar, en la sociedad". Se señala como una de las limitaciones importantes para abordar: la desconexión entre los equipos psicosociales y los profesionales del ámbito biológico en las intervenciones en casos de malnutrición. Por otro lado se analiza el consumo de diferentes alimentos, de los considerados necesarios a otros cada vez más aleatorios (bebidas alcohólicas y analcohólicas y otros alimentos menos relevantes, pero saludables), entre el grupo de bajos recursos y el grupo control, para detectar deficiencias de consumo notables -en lo relativo a los alimentos básicos - y no tan marcadas en los demás casos. Ello lleva a una primera conclusión y es que no siempre se puede explicar la malnutrición como una limitación de un consumo derivada del coste de los productos. Sugieren los autores, que la propuesta metodológica cuantitativa de esta investigación, basada en la lógica de impacto, aunque limitada por la muestra y por su vinculación a una sola entidad social a la que pertenece algún investigador, es apropiada por la validación de los resultados $\mathrm{y}$, por lo tanto, se podría generalizar y aplicar al diseño a programas de lucha contra la inseguridad alimentaria, partiendo de análisis rigurosos de las características nutricionales de los usuarios de ayudas alimentarias. También sentaría las bases para mejorar la nutrición de los destinatarios de estos programas de ayuda, o de otros programas de prevención de la obesidad. Por un lado, porque se pueden detectar algunos déficits en los modelos alimentarios de los hogares beneficiarios de ayudas alimentarias; y por el otro, porque si los usuarios no cumplen las recomendaciones nutricionales indicadas, la ayuda gestionada bajo una lógica de impacto social, puede seleccionar adecuadamente las prestaciones o los alimentos ofrecidos, desarrollando las destrezas que habrían de tener las personas beneficiarias para mantener dietas equilibradas y saludables, así como los cambios que se desean lograr en los 
contextos sociales donde estas desarrollan su vida cotidiana, apuntan los autores.

Con el último número de 2018 concluye la tarea de secretaria de redacción y miembro del Consejo Editorial de Cuadernos de Trabajo Social, que durante ocho años ha desempeñado quien firma esta presentación. Tanto tiempo en Cuadernos de Trabajo Social, en este espacio de conocimiento crítico, de debate, de aprendizaje recíproco y de sociabilidad ha sido increíble por inestimable. Han hecho posible que mantenga el entusiasmo unos directores con gran capacidad intelectual y organizativa, que con su sentido de responsabilidad supieron elegir a los miembros del Consejo editorial y del Consejo asesor; así como proponer, y aceptar las propuestas, de un equipo de evaluadores externos, que aunque parezcan muchos nunca son suficientespara la revista, que sin sus criterios y su disposición han valorado y valorarán la calidad de los artículos. Con todos ellos ha sido posible aceptar y cumplir con los desafíos de calidad científica que continuamente plantean entidades como FECYT y otras. También la incorporación a la plataforma OJS ha contri- buido a estrechar lazos profundos entre los miembros del petit comité -la Permanentequienes con cierta regularidad se encontraban en el despacho de la revista para proponer y resolver, junto con Claudia, Lisbeth, Carla y Tuca y Marimar, cuanto problema se planteara y propuesta se hiciera para dinamizar este espacio de sociabilidad. También con el apoyo constante de Eduardo, Maite y Leticia del servicio de publicaciones de la UCM que puntualmente han resuelto dudas, informado de éxitos, congresos y nuevas bases de datos; y ni qué decir tiene, la contribución de Elena, Steve y Cecilia para hacer comprensibles a los lectores el inglés y el francés. Mano a mano, con entusiasmo y con dedicación han hecho lo imposible para que los artículos salieran a tiempo y Cuadernos de Trabajo Social sea una revista de calidad.

Me alegro de haber pasado tanto tiempo con vosotros.

Teresa García Giráldez Universidad Complutense de Madrid, España matgarci@ucm.es 